\title{
A Narrative Review of the Patient Journey Through the Lens of Non-communicable Diseases in Low- and Middle-Income Countries
}

\author{
Ratna Devi (D) Komal Kanitkar · R. Narendhar · Kawaldip Sehmi • \\ Kannan Subramaniam
}

Received: August 6, 2020 / Accepted: September 28, 2020 / Published online: October 14, 2020

(c) The Author(s) 2020

\begin{abstract}
Low- and middle-income countries (LMICs) are challenged with a disproportionately high burden of noncommunicable diseases (NCDs) and limited healthcare resources at their disposal to tackle the NCD epidemic. Understanding the patient journey for NCDs from the patients' perspective can help healthcare systems in these settings evolve their NCD care models to address the unmet needs of patients, enhance patient participation in their management, and progress towards better outcomes and quality of life. This paper aims to provide a theoretical framework outlining common touchpoints along the patient journey for NCDs in LMICs. It further
\end{abstract}

R. Devi $(\bowtie)$

Dakshayani and Amaravati Health and Education, Gurgaon, India

e-mail: ratna.devi@dakshamahealth.org

R. Devi · K. Sehmi

International Alliance of Patient Organizations, London, England

K. Kanitkar

EPI (Immunization), Municipal Corporation of

Greater Mumbai, Mumbai, India

R. Narendhar

Alzheimer's Related Disorders Society of India

(ARDSI), New Delhi, India

K. Subramaniam

Upjohn-A Pfizer Division, Sydney, Australia aims to review influencing factors and recommend strategies to improve patient experience, satisfaction, and disease outcomes at each touchpoint. The co-occurrence of major NCDs makes it possible to structure the patient journey for NCDs into five broad touchpoints: awareness, screening, diagnosis, treatment, and adherence, with integration of palliative care along the care continuum pathway. The patients' perspective must be considered at each touchpoint in order to inform interventions as they experience firsthand the impact of NCDs on their quality of life and physical function and participate substantially in their disease management. Collaboratively designed health communication programs, shared decision-making, use of appropriate risk assessment tools, therapeutic alliances between the patient and provider for treatment planning, self-management tools, and improved access to palliative care are some strategies to help improve the patient journeys in LMICs. Long-term management of NCDs entails substantial self-management by patients, which can be augmented by pharmacists and nurse-led interventions. The digital healthcare revolution has heralded an increase in patient engagement, support of home monitoring of patients, optimized accurate diagnosis, personalized care plans, and facilitated timely intervention. There is an opportunity to integrate digital technology into each touchpoint of the patient journey, while ensuring minimal interruption to patients' care in the face of global health emergencies. 
Keywords: Noncommunicable disease; Patient engagement; Patient journey; Patient journey mapping; Patient journey touchpoints

\section{Key Summary Points}

In low- and middle-income countries with limited healthcare resources, where over three-quarters of noncommunicable disease (NCD) deaths occur, mapping the patient journey for NCDs can inform decision-making for designing and prioritizing interventions to optimize disease control and management.

This review summarizes the key touchpoints that are common along the patient journey for NCDs in the context of low- and middle-income countries: awareness of disease and knowledge of associated risk factors; screening and risk assessment; diagnosis and treatment decision; treatment experience and access to care; adherence to treatment for chronic management; and palliative care along the care continuum pathway.

In order to effectively improve the overall quality of care, it is important to adopt patient-centric strategies along these common touchpoints. Examples of such strategies include collaboratively designed health communication programs, shared decision-making, use of appropriate risk assessment tools, therapeutic alliances between the patient and provider for treatment planning, self-management tools, and improved access to palliative care.

Digital health technologies should be integrated into the patient journey to help healthcare systems and providers remain patient-centric while moving towards a public health approach focused on prevention and delay of onset of NCDs or complications, early and accurate diagnosis, and ensuring good adherence to treatment.

\section{DIGITAL FEATURES}

This article is published with digital features to facilitate understanding of the article. You can access the digital features on the article's associated Figshare page. To view digital features for this article go to https://doi.org/10.6084/m9. figshare.13014350.

\section{PLAIN LANGUAGE SUMMARY}

In low- and middle-income countries, patients living with noncommunicable diseases face several challenges due to limited healthcare resources, access to accurate information, and prevailing social, economic, and cultural conditions. These factors influence care pathways, patient behavior, and consequently the patient journey. A patient journey is defined as the sequence of steps beginning with a patient's awareness that something is not right or they are not feeling well and seeking interaction with hospital, healthcare professional, or other stakeholders in a healthcare system. Understanding these interactions can provide many insights into patient experience and the outcomes of their disease. In the context of patients suffering from noncommunicable diseases, these interactions can be broadly categorized as (1) awareness of disease and knowledge of associated risk factors; (2) screening and risk assessment; (3) diagnosis and treatment decision; (4) treatment experience and access to care; and (5) adherence to treatment for longterm management. The examination of these key patient journey touchpoints highlights opportunities in noncommunicable disease management and can help in prioritizing interventions for improving prevention and control. Strategies to improve the patient journey must integrate the patients' perspective at each touchpoint. Digital health technologies and widespread use of mobile phones in lowand middle-income countries allow patients to actively participate in their care through home monitoring devices, healthcare apps, wearable technology, and telehealth services. 


\section{INTRODUCTION}

Noncommunicable diseases (NCDs) are the leading cause of deaths globally, particularly in low- and middle-income countries (LMICs) [1]. The NCD mortality burden is disproportionately higher in LMICs, with over $75 \%$ of global NCD-related deaths [1]. Apart from the impact on health and well-being, NCDs also pose high financial burden on the national healthcare systems and often lead to catastrophic expenditure by households, particularly the poor who are the most affected [2]. Research on the major NCDs, i.e., cardiovascular (CV) diseases, diabetes, cancer, chronic respiratory diseases, and mental health disorders, informs that these conditions are associated with modifiable risk factors (tobacco and excessive alcohol use, unhealthy diet, and physical inactivity) that are common to them, and contribute to the disease onset [3]. Despite global commitment to reduce NCD-related premature mortality, progress is slow particularly in the LMICs [4]. This highlights the need to recalibrate the existing NCD care model.

\section{Patient Journey Mapping}

Patient journey mapping-also called healthcare process mapping-is an exercise used by healthcare leaders for viewing the management of specific conditions from the patients' perspective, as a series of consecutive events or activities between patients and healthcare systems that shape the patient experience $[5,6]$. From a hospital or healthcare system perspective, most patient journeys typically comprise six sequential stages as described in Table 1. Mapping reveals every facet of interaction between the patient and the health system, including appointment reminders, phone calls with admitting staff, prescription reminders, physical care, and with adequate surveillance, even points in the clinical journey that happen out-of-network [5]. This exercise helps locate any gaps in the patient care experience, lending the opportunity to redesign patient pathways to maximize clinical efficiency by focusing on activities most valued by patients [6]. To get the most out of the patient journey mapping exercise, it is important to identify various elements of the patient and health system interaction, as listed in Table 2. Despite their usefulness, there is no consensus on a universally accepted definition of the patient journey ratified by patients or patient organizations, varying between disease conditions, regions, and mapping process employed $[7,8]$.

Published studies have attempted to map patient journeys for individual NCDs in multiple countries and regions (Table 3) [9-14]. As expected, most evidence comes from high-income countries and the corresponding data for LMICs is sparse. Notably, most patient journeys for NCDs begin long before the "trigger" or point of access into the health system [9] - a fact that is commonly missed by healthcare providers and results in remedial counselling at or after the trigger. Being "aware" of NCD risk factors and adopting healthy lifestyles can prevent or delay the onset of a disease [15]. It is also important to recognize that NCDs do not occur in silos; many patients face multimorbidity, with each morbidity prompting its own unique journey [16]. Patients' perspectives and valueadded inclusion can provide both unique and critical insights to healthcare delivery teams in journey mapping. Patients living with NCDs (PLWNCDs) have direct, extensive experience of living with the disease and understand firsthand the impact of the disease on their quality of life and physical function. Chronically ill patients are expected to participate substantially through self-care in managing their adherence to therapy and the safe use of prescribed medicines based on labelling and other information provided to them [17].

\section{Barriers to NCD Care Pathways in LMICs}

Patient journeys are context-specific and reliant on national healthcare systems and investments. Since LMICs tend to have fragmented health service delivery, uneven quality of care, and a large informal healthcare sector providing substantial chronic healthcare, the patient journey from initial outreach to continued care is rarely seamless [18]. Equitable access to health 
Table 1 A healthcare system perspective of a patient journey

\begin{tabular}{|c|c|}
\hline Trigger event/awareness & $\begin{array}{l}\text { The patient self-assesses his or her symptoms, conducts research, considers potential health } \\
\text { conditions that may require treatment, and may even reach out to online communities (posing } \\
\text { questions on social media, etc.) }\end{array}$ \\
\hline Help & $\begin{array}{l}\text { The patient makes initial contact with a health system via a call center, chat, email, mobile, or an } \\
\text { in-person visit }\end{array}$ \\
\hline Care & The patient is assessed at a medical facility (physician's office, hospital, etc.) \\
\hline Treatment & $\begin{array}{l}\text { The health system provides the patient with both on-site and follow-up care (prescriptions, } \\
\text { physical therapy, counselling, or suggested lifestyle changes) }\end{array}$ \\
\hline $\begin{array}{l}\text { Behavioral/lifestyle } \\
\text { change }\end{array}$ & $\begin{array}{l}\text { The patient makes changes to daily routines and takes part in proactive healing in order to reduce } \\
\text { readmissions and promote long-term well-being }\end{array}$ \\
\hline $\begin{array}{l}\text { Ongoing care/proactive } \\
\text { health }\end{array}$ & $\begin{array}{l}\text { The patient manages his or her care between clinical visits; meanwhile, the health system fosters } \\
\text { engagement between the patient and physician in order to enable the patient to address } \\
\text { symptoms and maintain good health }\end{array}$ \\
\hline
\end{tabular}

Table 2 Key elements of a patient journey map

Touchpoints Any point of interaction between a patient and the healthcare system
$\begin{aligned} & \text { Timeline } \\ & \text { It is important to denote the amount of time that each interaction (or touchpoint) lasts, the amount of } \\ & \text { time in between touchpoints, and the overall length of the patient journey }\end{aligned}$
$\begin{aligned} & \text { External } \\ & \text { influences }\end{aligned}$
$\begin{aligned} & \text { Internal } \\ & \text { influences }\end{aligned}$
$\begin{aligned} & \text { Any factors that impact the patient journey that are beyond the health system's control. For instance, if } \\ & \text { instance, a long wait time to schedule a surgery due to the renovation of a surgical wing within the } \\ & \text { hospital } \\ & \text { Any factors that may prevent the patient journey from moving forward. Examples of common barriers } \\ & \text { within the patient journey include cost (if the patient is unable to afford continued treatment), time } \\ & \text { conflicts (such as a hectic work schedule or family obligation), the patient's mental or emotional state, } \\ & \text { socioeconomic pressures, and many others }\end{aligned}$

services is far from optimal in many LMICs, as evident from poor patient-to-provider ratios and high out-of-pocket (OOP) expenditure on healthcare $[19,20]$. Whereas in developed nations the OOP expenditure for complete healthcare (data for NCD OOP expenditure is not reported separately) is about $20-25 \%$, it rises to a massive $60 \%$ in developing countries like India [21, 22]. Contributing to the burden, most LMICs invest only a small proportion of their gross domestic product into healthcare expenditure (ca. 4\%), much lower than what is needed [23].

In LMICs, several factors outside the health system also influence decisions to enter or exit the patient journey, and often these choices influence the disease trajectory. Poor health literacy and lack of awareness about risk factors and appropriate entry points into the healthcare system contribute to poor patient 
Table 3 Comparison of patient journey mapping approaches for select NCDs

\begin{tabular}{|c|c|c|c|}
\hline Study & NCD & Region $^{a}$ & Stages outlined \\
\hline $\begin{array}{l}\text { Thrift-Perry } \\
\text { et al. [9] }\end{array}$ & Breast cancer & HIC, LIC, MIC & $\begin{array}{l}\text { Awareness/recognition } \\
\text { Diagnosis } \\
\text { Coordinated care } \\
\text { Treatment } \\
\text { Ongoing management }\end{array}$ \\
\hline $\begin{array}{l}\text { Mohr et al. } \\
{[10]}\end{array}$ & Schizophrenia & HIC (Europe) & $\begin{array}{l}\text { Premorbid phase/preventive measures } \\
\text { Prodromal phase/early detection, early intervention } \\
\text { Acute episode/treatment initiation } \\
\text { Long-term phase/relapse prevention } \\
\text { Recover }\end{array}$ \\
\hline $\begin{array}{l}\text { Fennelly et al. } \\
\text { [11] }\end{array}$ & $\begin{array}{l}\text { Musculoskeletal } \\
\text { disorders }\end{array}$ & HIC (Ireland) & $\begin{array}{l}\text { First clinician appointment } \\
\text { Subsequent clinician appointment } \\
\text { Investigations } \\
\text { APP appointment } \\
\text { Initial referral } \\
\text { Additional APP appointment }\end{array}$ \\
\hline $\begin{array}{l}\text { Sköld et al. } \\
\text { [12] }\end{array}$ & $\begin{array}{l}\text { Idiopathic } \\
\text { pulmonary } \\
\text { fibrosis }\end{array}$ & HIC (Sweden) & $\begin{array}{l}\text { Time to disease diagnosis } \\
\text { Medication use } \\
\text { Treatment pattern } \\
\text { Adherence, persistence, and length of treatment }\end{array}$ \\
\hline $\begin{array}{l}\text { Kassouf et al. } \\
\text { [13] }\end{array}$ & Bladder cancer & HIC (Canada) & $\begin{array}{l}\text { Pre-diagnosis (signs/symptoms) } \\
\text { Time of diagnosis/pre-treatment } \\
\text { During treatment } \\
\text { After treatment (living "the new normal") }\end{array}$ \\
\hline
\end{tabular}


Table 3 continued

\begin{tabular}{|c|c|c|c|}
\hline$\overline{\text { Study }}$ & NCD & Region $^{a}$ & Stages outlined \\
\hline Alkandari et al. [14] & $\begin{array}{l}\text { Peripheral } \\
\text { neuropathy }\end{array}$ & HIC (Kuwait) & $\begin{array}{l}\text { GP visit in primary care } \\
\text { Blood test } \\
\text { General pain management } \\
\text { Referral to general hospital } \\
\text { Complete investigations } \\
\text { Continue general pain management } \\
\text { Referral to neurologist in general hospital } \\
\text { Advanced investigations } \\
\text { Continue general pain management and } \\
\text { first-line treatment } \\
\text { Referral to neurology specialist in national hospital } \\
\text { Advanced investigations and physical examination } \\
\text { Continue general pain management and } \\
\text { first-line treatment and start second-line } \\
\text { or third-line treatment } \\
\text { Follow-up, monitoring, and review medications }\end{array}$ \\
\hline
\end{tabular}

$\overline{A P P}$ advanced practice physiotherapist, GP general physician, HIC high-income countries, LIC low-income countries, MIC middle-income countries, $N C D$ noncommunicable disease

${ }^{a}$ Classified according to the World Bank income classification

outcomes [24, 25]. In resource-limited settings, unauthorized practitioners propagate ignorance, misconceptions, and misleading guidance that complicate patient pathways further [26]. Health and morbidity are influenced by behavioral decisions of individuals or their families, genetically inherited health endowments, or the health environment in which people reside. Illness is, therefore, systematically linked to household- and community-level factors [27]. Other factors shaping health-seeking behavior include age, socioeconomic conditions, presence of comorbidities, perceived family support, duration of disease, and history of early treatment at diagnosis [28]. The social determinants of health in LMICs, governed by the policy choices and the amount of money, power, and resources that people have, are key to discerning care pathways followed by patients when accessing healthcare [29]. The differences in healthcare systems, socioeconomic and cultural factors, and population health literacy warrant the need for examining patient journeys independently in the LMIC setting.

\section{Scope of the Study}

NCDs often co-occur and share common behavioral and environmental risk factors. The World Health Organization (WHO) has long advocated for an integrated approach for prevention and control of NCDs both at system and service levels, rather than in disease-specific silos [30]. Therefore, this paper aims to provide a theoretical framework outlining the shared patient journey touchpoints for people living with the major NCDs, particularly CV diseases, 
diabetes, and mental health disorders, as the leading contributors of NCD-related mortality and morbidity in LMICs [1]. It further aims to draw upon published literature and secondary sources to review influencing factors and recommend patient-centered strategies to improve the patient journey at each touchpoint.

\section{METHODS}

The PubMed database was searched to identify relevant literature using the search terms "patient-centered care", "patient journey", "noncommunicable diseases", "cardiovascular diseases", "diabetes", "hypertension", "dyslipidemia", "mental health", "depression", "anxiety", "awareness", "health promotion", "health literacy", "patient education", "screening", "risk assessment", "diagnosis", "treatment decision", "treatment experience", "treatment monitoring", "treatment access", "adherence", "compliance". As a result of the sparse availability of peer-reviewed literature on the topic in LMICs, additionally, relevant articles and reports curated by the authors from the Google database and gray literature were also utilized in this study.

This article is based on previously reported studies and does not contain any studies with human participants or animals conducted by any of the authors.

\section{RESULTS}

\section{Common Touchpoints of the Patient Journey for NCD in LMICs}

Suffice to say that patient journeys are not similar for all diseases; however, there are commonalities in patient journeys of closely linked groups of diseases and specific needs for individual conditions [31]. The WHO recommends integrated management of NCDs with equitable access to a nationally determined set of promotive, preventive, curative, rehabilitative, and palliative basic health services [32]. Aligned with the WHO recommendation and common risk factors linking the major NCDs
[33], the patient journey for NCDs can be structured into five broad touchpoints: awareness, screening, diagnosis, treatment, and adherence with integration of palliative care along the care continuum pathway (Fig. 1).

The importance of the concept of primordial prevention, which focuses on health education even before risk factors arise, cannot be downplayed in the context of NCDs [34]. Awareness of health-promoting habits and knowledge of disease form the first stage of the patient journey, before the onset of NCDs [35]. Periodic or opportunistic screening for risk factors and cooccurring NCDs is an effective strategy for lowering the morbidity and mortality due to these diseases by detecting undiagnosed cases and initiating early treatment [36]. At the remedial phase, the treatment decision following diagnosis, treatment experience influenced by treatment goals, access to services, follow-up, and adherence to the recommended therapeutic or lifestyle modification interventions determine the course of the patient journey for NCDs and the outcomes. Palliative care is recognized as an integral component of universal health coverage and must be available throughout the life course of PLWNCDs particularly in LMICs, where approximately $80 \%$ of the global population in need of palliative care resides $[37,38]$. Palliative care is essential for better control of symptoms and an improved quality of life for patients and also improves the physical and psychosocial well-being of families and caregivers [38].

The patient's touchpoints with healthcare systems along their journey is further influenced by the accessibility of services across five dimensions, i.e., approachability, acceptability, availability and accommodation, affordability, and appropriateness (Fig. 2) [39]. These dimensions in access to care are in turn governed by the patient's ability to perceive, ability to seek, ability to reach, ability to pay, and ability to engage, respectively [39]. Strategies designed to improve the patient journey must consider these factors to ensure a patient-centered perspective. 


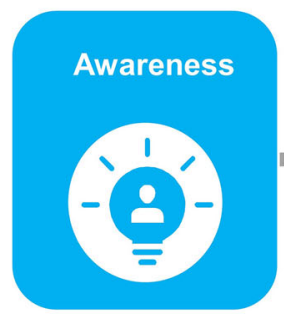

Health Promotion Disease Awareness, Patient Education

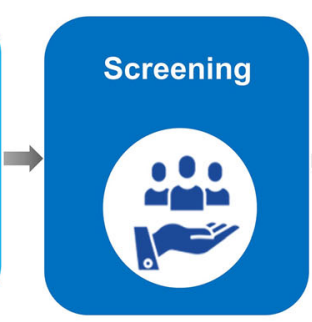

Disease Screening Risk Assessment

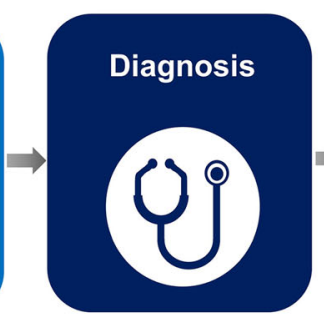

Diagnosis by HCP, Treatment Decision

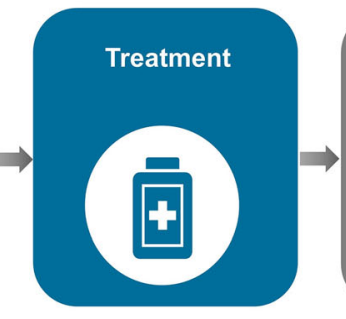

Treatment Experience, Monitoring, Access to Care

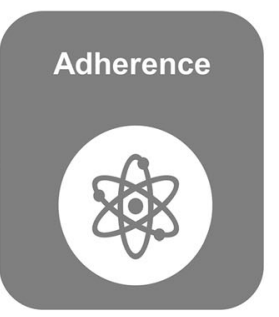

Compliance to

Therapy, Chronic Management

\section{Palliative Care}

Fig. 1 Key touchpoints of the patient journey for noncommunicable disease. $H C P$ healthcare professional

\section{Strategies to Improve the Patient Journey for NCDs Along Common Touchpoints}

Improving the patient journey for NCDs requires cost-effective and efficient solutions customized to LMIC settings [40]. It is important to review problems and prospects of influencing factors at the micro, meso, and macro levels of healthcare, i.e., at the level of individuals, their households, and communities, as well as at the policy level [41]. Some recommendations are listed in Table 4.

\section{Disease Awareness and Knowledge of Associated Risk Factors: Effective Health Communication}

The limited impact of the medical monologue between the doctor and the patient, guised as medical communication, has necessitated the development of health communication strategies that are collaboratively designed, implemented, and comprehensively evaluated to ensure sustainable health improvements $[42,43]$. The overarching component of an effective health communication program remains a powerful, well-articulated, long-term vision. In chronic conditions like heart failure, transition from home to hospital can be high risk. Preventing rehospitalization requires integration of care across hospitals, home care agencies, and outpatient clinics and patient education [44]. Evidence suggests that increasing "patient activation" interventions-the skills and confidence that equip patients to become actively engaged in their healthcare-is linked to improved outcomes and reduced relapses and rehospitalizations [45].

Although physicians report attempts to educate patients on the causes of their disease and the importance of adhering to secondary prophylaxis, patients in LMICs still have very low levels of understanding of their disease [46]. There is potential to address the underlying issues by involving caregivers during consultation, use of native language while providing therapy or counselling, observing cultural nuances and levels of literacy. Awareness of the patients' needs and cultural background should take precedence in the conversation around expectations of adherence of follow-up; physicians explanations and the level of patients' understanding significantly affect treatment adherence, treatment outcome, and patients' satisfaction [47]. Healthcare providers need to be critically aware of these issues when communicating with patients and their caregivers, select health information that is appropriate to the patients' level of 


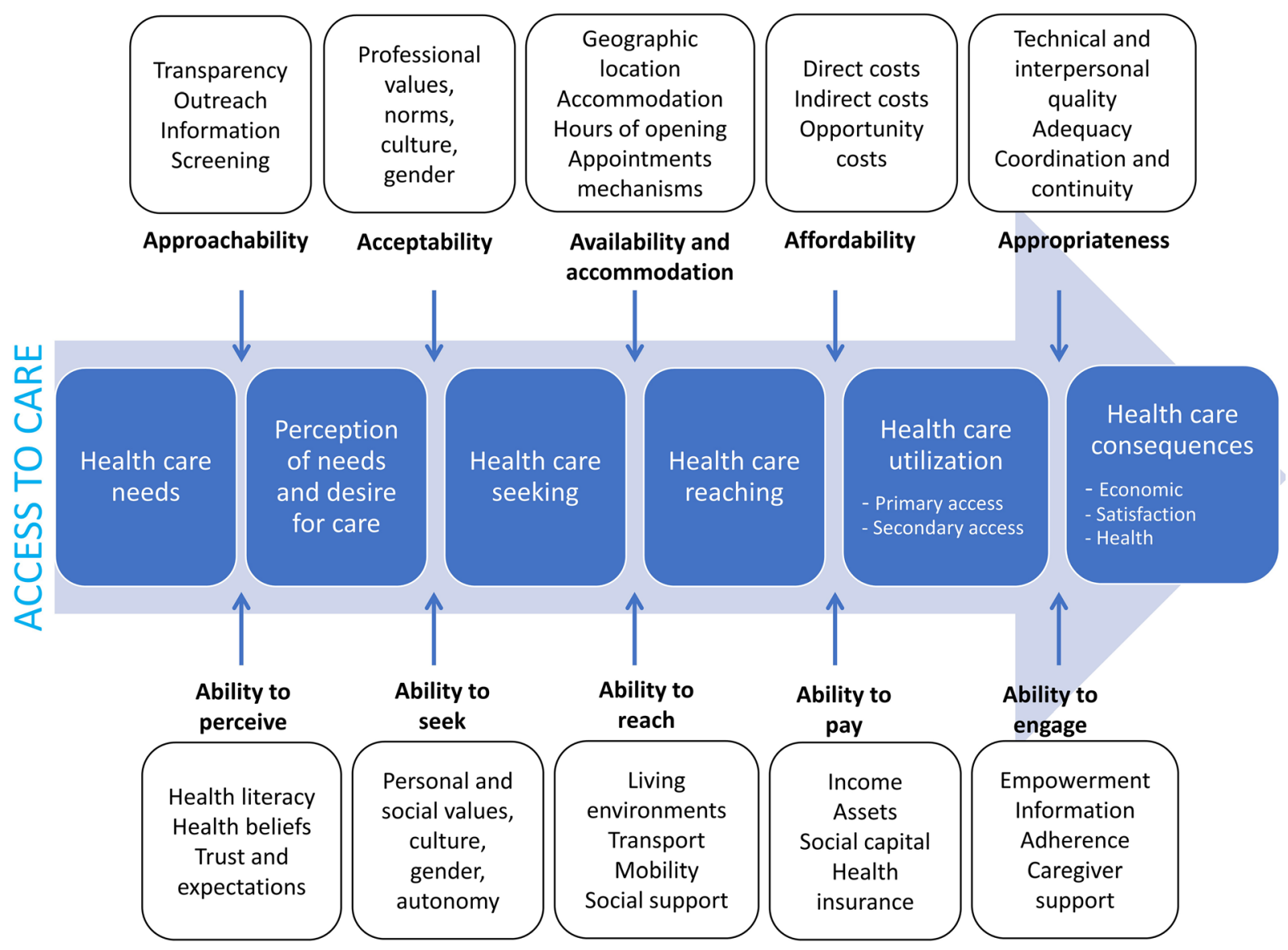

Fig. 2 A conceptual framework of barriers and facilitators in access to healthcare. Reprinted from "Levesque, J., Harris, M.F. and Russell, G. Patient-centered access to health care: conceptualizing access at the interface of health systems and populations. Int J Equity Health 12, 18

understanding, and employ a systematic approach using a basket of tools (e.g., printed material, displays, videos, and discussions) to educate and improve awareness and stress motivating principles, cultural relevance, and feasibility [47].

\section{Screening and Risk Assessment: Integrated Assessment Tools for NCDs}

Screening for risk factors is a cost-effective method for early diagnosis and further prevention of complications. As a result of limited knowledge on the prevention aspects of $\mathrm{CV}$ diseases, people living in LMICs often delay visiting hospitals at the first sign/symptom [48].
(2013)” [Copyright (C) 2013, Springer Nature] published under license to BioMed Central Ltd. as indicated under the terms of the Creative Commons Attribution License (https://creativecommons.org/licenses/by/2.0)

$\mathrm{CV}$ risk screening and stratification of high-CVrisk individuals, based on multiple risk factors (age, sex, blood pressure, blood lipids, smoking, diabetes), can detect subclinical CV diseases and avert future CV events [49]. The WHO PEN package tools provide specific guidance for screening, risk stratification, and management of patients with the main NCDs in low-resource settings [49]. Notably, failure to detect underlying mental illnesses leads to underestimation of overall CV risk, deters prognosis and adherence to treatment, and can impact the patient journey [50]. Mental health issues often co-occur with other NCDs [33]. People with debilitating neurological disorders like stroke, Parkinson's disease, and epilepsy are often 
Table 4 Summary of recommendations to improve the patient journey for NCDs

\begin{tabular}{|c|c|}
\hline $\begin{array}{l}\text { Touchpoint during patient } \\
\text { journey for NCDs }\end{array}$ & Recommendations \\
\hline \multirow[t]{4}{*}{ Awareness } & $\begin{array}{l}\text { Utilize integrated communication messages combining disease information with } \\
\text { health-promoting habits, where possible }\end{array}$ \\
\hline & $\begin{array}{l}\text { Utilize mobile phones, web-based technologies, and electronic and social media to } \\
\text { provide cost-effective education solutions for large populations }\end{array}$ \\
\hline & $\begin{array}{l}\text { Involve the local community with a strong consultative process to align with language, } \\
\text { cultural, and religious differences }\end{array}$ \\
\hline & Apply integrated services (e.g., physiotherapy and counselling) across all NCDs \\
\hline \multirow[t]{3}{*}{ Screening } & Develop risk stratification tools for primary and secondary prevention of CVDs \\
\hline & Screen for mental health issues during routine checkups in primary care settings \\
\hline & Perform age-appropriate screening to inform best-fit treatment options \\
\hline \multirow[t]{3}{*}{ Diagnosis } & Promote shared decision-making to improve decision-related outcomes \\
\hline & $\begin{array}{l}\text { Utilize decision aids to inform patients on the potential benefits, risks, and costs of } \\
\text { available treatments }\end{array}$ \\
\hline & Engage families and caregivers in decision-making \\
\hline \multirow[t]{5}{*}{ Treatment } & Ensure supply of good-quality affordable generic medicines \\
\hline & Include essential NCD medicines in healthcare benefits packages \\
\hline & Maintain uninterrupted supply chain of medicines \\
\hline & Follow patient-centered care approach to treating NCDs \\
\hline & Utilize personalized treatment goals \\
\hline \multirow[t]{5}{*}{ Adherence } & $\begin{array}{l}\text { Encourage pharmacist-led interventions for education and counselling for medication- } \\
\text { related issues }\end{array}$ \\
\hline & Expand role of nurses in patient follow-up particularly for adult patients \\
\hline & Train community health workers to drive health literacy \\
\hline & Develop "expert patient" programs \\
\hline & Utilize e-health technologies to improve medication adherence \\
\hline \multirow[t]{3}{*}{ Palliative care } & Integrate palliative care in national health policies \\
\hline & Ensure access to essential pain medicines \\
\hline & Train health professionals in imparting palliative care \\
\hline
\end{tabular}


Table 4 continued

\begin{tabular}{ll}
$\begin{array}{l}\text { Touchpoint during patient } \\
\text { journey for NCDs }\end{array}$ & Recommendations \\
\hline $\begin{array}{l}\text { Digital health } \\
\text { Merge biomarkers with social media footprint to predict risk more accurately and } \\
\text { prompt customized interventions } \\
\text { Develop affordable wearable technology } \\
\text { Develop applications for home monitoring of treatment outcomes } \\
\text { Support patient self-management linked with healthcare teams via "digital umbilical } \\
\text { cord" } \\
\text { Innovate on patient facing tools for elderly patients to improve quality of life, facilitate } \\
\text { communication with providers, and aid decision support }\end{array}$ \\
\hline
\end{tabular}

$C V D$ cardiovascular diseases, $N C D$ noncommunicable diseases

treated for the disease alone and the mental health aspect is excluded. On the other hand, mental health issues like depression are often hidden and overlooked during routine checkups. Primary care clinics are an ideal setting to identify and address mental health problems early, although integration of mental health services within primary care and in communitybased settings remains low [51].

Age-appropriate screening is important to understand the best fit for treatment options and care pathways. A pediatric patient with cancer would need a different approach compared with an elderly patient with stroke. The guidance provided, choice of treatment plans, and discharge advice should be based on the age and fitness of the patient, which is often overlooked in busy clinical practice. For senior citizens, a geriatric assessment is a valid strategy to stratify patients and prepare them for care pathways. A variety of fitness/frailty scores are available to appropriately assess the status of elderly patients [52].

\section{Diagnosis and Treatment Decision: Shared Decision-Making}

The true extent of those at risk for NCDs or those who have NCDs is likely underestimated, given that many persons with raised blood pressure and diabetes remain undiagnosed $[53,54]$. Early diagnosis is critical to prevent complications and ensure optimal treatment outcomes. However, this is based on several critical factors of access, awareness, and affordability. Clinician-patient risk discussions must follow the approach of shared decision-making in which the patient and physician consider the potential benefits of treatment, risk of adverse events, and patient preferences before making a final decision to initiate treatment [55].

Shared decision-making and self-directed support have the potential for being effective tools for recovery [56]. It is important to consider patients and their families as critical partners in the diagnostic process. Their engagement will result in a valuable contribution to facilitate an accurate and timely diagnosis and improve shared decision-making on treatment and continued care [57]. In conditions like advanced heart failure, the treatment goal is to improve quality of life and prolong survival [56]. Shared decision-making for advanced therapies in these conditions must be considered in the context of the caregivers' ability to manage tailored treatment [56]. For patients who are unable to make decisions themselves or independently follow the treatment and care pathways, clinicians need to 
effectively engage with caregivers and family [56].

Decision aids can facilitate shared decisionmaking and improve decision-related outcomes, particularly involving multiple treatment choices [58]. Often the choice of treatment is weighed down heavily by the patients' ability to pay at the time of treatment. However, the benefit of choosing a seemingly expensive option with better outcomes that saves on long-term treatment and fewer complications is often not explained well enough to the patient [59]. Use of decision aids reduced decisional conflict, and increased knowledge and satisfaction without any change in anxiety or depression, in many studies [58, 59]. Additionally, the utility of clinical practice guidelines to aid diagnosis and treatment cannot be ignored. The guidelines contain recommendations that are based on evidence from rigorous systematic reviews and synthesis of the published medical literature [60].

The importance of integrated primary healthcare services and management of chronic diseases is gaining momentum and the artificial dichotomy between diseases is slowly receding in favor of a combined approach that benefits all conditions [61]. This integration of comprehensive services, especially within existing and established primary and secondary healthcare structures, should be strongly encouraged by clinicians, policy makers, and the community.

\section{Treatment Experience and Access: Patient- Centered Approach}

Once diagnosed, PLWNCDs face many challenges in accessing treatment due to availability and affordability of essential NCD medicines in these settings. Governments must commit to long-term strategies to address access-related issues pertaining to regulatory (ensure good quality of medicines in circulation and acceptance of affordable generic medicines), healthcare financing (inclusion of priority NCD medicines in benefits packages and reduce OOP expenditure), and supply chain matters (efficient procurement and distribution of medicines) [62].

Many experts have indicated that "chronic diseases are managed most effectively when patients take an active role in this themselves" [63]. Empowerment is the result of effective communication in healthcare and determines consequent participation and self-management [64]. "Therapeutic alliance" is a concept in the field of psychiatry that refers to the relationship between a healthcare provider and patient [65]. An optimal therapeutic alliance is achieved when the patient and the therapist share beliefs in the relevance of treatment goals and efficacy of the strategies to achieve those goals. A positive therapeutic alliance is a predictor of patient activation and positive clinical outcomes $[65,66]$.

Patient-centered care (PCC) identifies patients as partners with their healthcare providers and recognizes an individual's specific health needs and preferences as the driving force in all healthcare decisions [63]. PCC encourages the presence of family members in care settings and respects their values, cultural traditions, and socioeconomic conditions. PCC has the benefit of improving patient satisfaction levels, improving the productivity of clinicians and ancillary staff, and reduces expenses across the continuum of care. Management of chronic conditions is moving toward an individualized therapy approach; personalized treatment goals for conditions such as diabetes can be valuable in providing effective care and also combating negative long-term outcomes [67].

\section{Adherence for Long-Term Management: Self- Management Tools}

The medication adherence rate, defined as the extent to which patients take medication as prescribed by their healthcare professionals, among patients in LMICs suffering from chronic diseases is about $50 \%$, a worrisome statistic [68]. Evidence has demonstrated that interventions led by clinical pharmacists encompassing services such as education, counselling, and assessing each medication and medication-related problem for patients with diabetes are effective in increasing adherence to clinical guidelines and medications leading to improved outcomes [69]. Older adults often face adherence issues following hospital discharge due to complex treatment plans and poor communication with the patient. Nurses are 
well placed to follow-up with these patients and keep them adherent to their therapies. Additionally, frontline community health workers and patient support groups can be instrumental in driving patient health literacy, empowerment, and ultimately medication adherence [70, 71]. Developing "expert patient" programs imparting peer education, training, and skill development can be a cost-effective strategy for driving adherence in LMICs [18]. Other tools applying innovative e-health technologies combined with pill counts can improve medication adherence among the vulnerable and older patients [68].

\section{Palliative Care: Integrating with Health Services}

Palliative care is still in its nascent stages in most developing countries. Pain and respiratory issues are the main complaints from patients in need of palliative care. As per the WHO, access to palliative care is a human right and national health systems must include palliative care in the continuum of care linking it to prevention, early detection, and treatment programs for chronic and life-threatening conditions [38]. The immediate actions include integrating palliative care into national health policy or action plans and ensuring funding and affordability of palliative care service delivery; building the capacity of health workforce to delivery palliative care through training and updating medical curricula; and ensuring the availability of essential medicines including opioids for pain relief $[38,72]$. Choice of palliative care service delivery models must be based on the cultural, spiritual, and economic needs of the people. Home-based palliative care is the most common service delivery model in LMICs [72]. Other models include outpatient clinics and day care where patients visit a palliative care facility for services [72, 73]. However, these models need involvement of families and volunteers for managing essential symptoms supplemented with healthcare professionals for necessary medicines and backup support $[72,73]$.

\section{Integrating Digital Technologies into the Patient Journey}

With the advent of smart phones, tablets, nimble wearables relying on big data, health informatics, and analytics, digital technologies have afforded the opportunity to monitor the complete patient journey in real time and provide patients with tools to better manage their journey $[74,75]$. The penetration of mobile telephones in LMICs has exceeded that of developed nations, leading to new possibilities in the field of healthcare [76]. This rise in technology adoption is shaping the medical ecosystems in many ways; within the NCD arena it provides health systems the opportunity to shift the balance from secondary to preventative care [77]. In the near future, physicians will have access to electronic medical records, real-world data, and patient-reported outcomes at their fingertips, which will restore patient-centricity within personalized healthcare. Recognizing this imminent transformation in healthcare, the WHO released guidelines on evidence-based digital health interventions for health system strengthening [78].

In the digital health age, the start of the new patient journey should ideally begin with the merging of patients' social media, geo-location, and other digital footprints with their biomarkers. Merging these digital footprints with biomarkers like blood pressure, glucose levels, and body mass index can predict raised risk levels [79]. Following that, a revised schedule of physical activity, diet and nutrition, and other routines drawn up with the health professional and fed into the patient's smart phones could drive the appropriate lifestyle changes.

Good personalized healthcare involves home-based supported self-care [80]. Digital solutions allow patients to benefit from homebased self-care while still being attached to their healthcare team through a "digital umbilical cord". Secondary prevention in self-care entails patients maintaining their blood pressure, blood glucose, lipids, and other endocrinal markers within a safe level either through prophylactic therapies or through lifestyle modifications [81]. With advances in home 
monitoring devices, these markers can be easily monitored by patients and the results transmitted to their health teams for analysis and treatment optimization. Use of simple fingerprick tests or automated machine learning solutions such as the flash glucose monitor or the continuous glucose monitor for diabetes mellitus and home blood pressure monitoring devices for hypertension have reported better outcomes for patients [82, 83]. These technologies provide a high resolution view of each patient and can facilitate the choice of individual optimal therapy.

As with all technological advancements, there is an expected lag in the adoption of digital developments by healthcare professional communities due to a lack of awareness, lack of understanding, resistance to digital technologies, and working within protected silos that discourage information sharing. Lastly, there are concerns from the patient community regarding data privacy and ownership, and fear of discrimination against certain genetic diseases [84].

\section{DISCUSSION}

The growing number of people living with chronic diseases is both a measure of success, an outcome of increased life expectancy, and a challenge for healthcare systems in LMICs [85]. Despite international commitment, the momentum for impeding NCD-related morbidity and mortality has waned since 2010 [86]. In contrast to developed countries where healthcare delivery remains relatively accessible and inclusive, LMICs require substantial improvements in healthcare delivery to meet the Sustainable Development Goals and achieve Universal Healthcare Coverage [87]. To effectively alter the current trajectory of NCDs, it is important to review problems and prospects of influencing factors at the micro, meso, and macro levels of healthcare, i.e., at the level of individuals, their households, and communities, as well as at the policy level [41]. Evidence suggests that patient experience is a key pillar of healthcare quality; therefore, instead of limiting it to in-person interactions between the patient and physician, mapping the entire patient journey is the best way to understand the patient experience and identify existing lacunae [88].

Traditionally, a patient journey is viewed from the perspective of healthcare providers. It is often perceived to be linear, following a sequential process in a care continuum pathway with a single entry and exit point. The entry point or the start of the patient journey is believed to begin after a "trigger" - an onset of a sign or symptom of a disease. Redesigning of patient pathways based on journey mapping is often undertaken with the purpose of improving healthcare system performance or meeting regulatory constraints [6]. Traditional patient journey maps also miss the impact of medical protocols followed in patient care [6].

The patient journey for NCDs starts well before an episode of care and continues after discharge $[89,90]$. The patient journey is also complex with multiple entry and exit points. In practice, care provided to patients with multimorbidity is fragmented, resulting in innumerable hospital appointments with different specialists and concurrent use of multiple medications or polypharmacy. The "treatmentin-silos" approach impacts patients' lifelong compliance to treatment and further incapacitates patients with advancing age and disability. There is a need to reframe the patient journey as one with touchpoints, where a patient may enter at any one point but often may need support and care at other points. For example, in the framework presented in Fig. 1, the NCD patient's first touchpoint may well be at "Diagnosis" during an encounter with the health system. They will benefit from education to increase their "Awareness" to help them understand and participate in their care; they may benefit from "Screening" for comorbidity; and enriched monitoring and counselling for "Adherence".

The concept of "healthcare" has been delineated from "medical care" years ago; still, most healthcare systems today subject PLWNCDs to only physical and laboratory evaluations without properly assessing their mental, social, and emotional well-being [91]. Following diagnosis, treatment modalities are tailored to the disease 
rather than the person, leading to altered lifestyle to suit protocols set up for the condition. There is a strong call to action in LMICs to integrate the management of NCDs combined with the "holistic medicine" concept that follows the approach of putting patients' perceived needs first in providing care not just for physical but also mental, emotional, and spiritual needs [71].

This can only be achieved through critical assessment of the underlying complexities in patient journeys for NCDs-awareness levels, screening opportunities, treatment protocols, access to care, issues with compliance-to avoid missteps in providing timely and optimal intervention.

It is increasingly evident that many PLWNCDs have specialized expertise and can play a crucial role in identifying what is most meaningful to them and their conditions. The "expert patient" concept where patients with significant knowledge about their disease and treatment take on a larger role in self-management has been explored in the West with noted improvements in symptoms, quality of life, and adherence [18]. Many healthcare systems in developed countries have found value in moving towards a self-management approach for chronic diseases, utilizing the knowledge and expertise held by "expert patients" [18, 92, 93]. Replication of this approach in LMICs has seen some success in positively impacting the patient journey. A diabetes peer education program (MoPoTsyo) initiated in rural and urban slum areas of Cambodia trained patients from local communities as peer educators who could then coach other patients in self-management, counsel them on lifestyle changes, and conduct follow-ups [94]. MoPoTsyo patients had better health outcomes in terms of a higher proportion of patients achieving target glycosated hemoglobin (HbA1C) levels, lower systolic blood pressure, and reduced presence of diabetes foot lesions and also had lower diabetesrelated healthcare expenditure compared with diabetes care programs in two other LMICs, Democratic Republic of Congo and the Philippines [95]. Access to more external resources and a stronger focus on self-management and chronic illness may have contributed to the success of MoPoTsyo [95]. Meaningfully involving PLWNCDs along common touchpoints in the patient journey for NCDs will help inform the value assessment in healthcare, provide better outcomes, and increase adherence to therapy, leading to a happier and more rewarding patient experience.

Use of mobile- and web-based computing can help in educating individuals at the level of prevention by emphasizing the control of NCD risk factors and, once made aware of their conditions, aids in self-management and adherence to their treatment. A systematic review identified that mobile solutions are more widely available than other technology-based solutions for education on NCDs owing to ease of access, convenient delivery of educational content, and potential to gamify educational learning for chronic illnesses [96]. Another review from developed countries demonstrated that the use of information and communication technology (ICT) in health promotion behavior resulted in increased physical activity, reduced weight, and healthy behavior change among the participants [97]. However, there is a dearth of data on the long-term effectiveness of ICT on healthpromoting behaviors in LMICs. There is an urgent need to build evidence for ICT use in promoting health behaviors among healthy adults in LMICs and move towards personalized assistance supported by ubiquitous learning $[96,97]$.

Social environments have a significant influence on an individual's health and, in this digital age, online social networks play an important role in health as they control access to resources and opportunities to model one's behavior [98]. Several models have been developed and evaluated the use of social media to foster better health behaviors among populations. For example, the Pompilos model was developed to enhance healthcare applications with social media content and ascertain to what extent a person's health behavior influences the health of others in their social network [98]. Preliminary evaluation of the model indicated that NCD prevention messages directed to users correlated with increased access to the application and warrants further research [98]. Most LMICs are progressing towards an ageing 
population that will accompany a rise in chronic conditions and increased healthcare costs [99]. From an elderly patient setting in LMICs, technology must prioritize patient-facing innovations that improve quality of life, facilitate communication with providers, and provide decision-support [99]. Redesigning healthcare models to sustain increased selfmanagement will improve outcomes and reduce healthcare costs. Healthcare applications can be further enhanced by integrating them into "smart city" infrastructures, e.g., the U'Ductor architecture developed in Brazil can increase social collaboration by integrating with city information systems to guide users to hospitals on the basis of the availability of beds, provide traffic updates in medical emergencies, recommend modes of transport on the basis of real-time air quality data, etc. [100].

\section{Future Perspectives}

The COVID-19 pandemic accelerated the digitization of healthcare services as health systems had to adopt telemedicine and other technologies to flatten the curve and help patients in self-isolation receive access to healthcare [101]. A WHO survey of 194 countries in May 2020 reported severe disruption to prevention and treatment services for NCDs since the beginning of the COVID-19 pandemic [102]. Preexisting inequities in LMIC health systems will likely exacerbate the effects of the COVID-19 pandemic among vulnerable populations and the care for chronic diseases will likely further worsen along with health outcomes. This may be the result of health system capacity being exceeded, redeployment of health personnel to the frontline of COVID-19 infection, or because of measures placed to address the spread of the pandemic such as lockdowns and restrictions on people's movement [103]. A prescient insight into the patient journey for NCDs can help with adopting the WHO guidance to maintain essential services for NCDs. The guidance offers programs of activities across chronic disease management including awareness; prevention and screening; diagnosis; specialist treatment; rehabilitation; and palliative care [104]. Increase in home-based service support by appropriately trained community health volunteers helps promote self-care, risk assessment, and referral for uncomplicated patients, a cost-effective strategy for prioritizing NCD management [105]. Being readily accessible healthcare practitioners in LMICs during the pandemic, community pharmacists are well positioned to help manage chronic conditions, promote medication adherence, and help ease the burden on already strained health systems [103].

Setting healthcare priorities is of particular importance in the LMICs in order to allocate their limited resources toward the most effective interventions. Evidence-based decisionmaking for NCD prevention and control policies requires reliable and timely data [106]. The lack of mechanisms to collect high-quality data is a major barrier to successful implementation and monitoring of NCD programs in LMICs [107]. As a result, NCD policy recommendations at the national and local levels in LMICs are based on evidence from communicable diseases or from studies conducted in high-income countries, which can potentially impact the outcomes of these policies [107]. Similarly, mapping patient journey for NCDs will require local evidence generation and continual monitoring of evidence to inform strategies to improve the patient journeys in LMICs.

The mounting mental health burden is a growing concern in LMICs, as poverty is known to be associated with increased risk of mental illness. Limited access to psychiatrists and mental health facilities in many LMICs has triggered the pursuit for innovative solutions such as employing community-based health workers to deliver psychosocial therapies supported remotely by specialists [108]. Additionally, technology-based solutions are being explored in the domain of mental health education and information dissemination, digital screening tools and diagnosis, self-management programs, and system-level efforts to improve mental health [108]. Several models of ubiquitous computing have been proposed to inform psychotherapeutic practice, often used in the treatment of depression and anxiety disorders [109]. Mobile and wearable technologies can be 
utilized to collect an individual's physiological and environmental measurements and provide psychophysiological insights [110]. Patient engagement and adherence to online programs in psychotherapeutic treatment can be improved by employing gamification techniques [109]. Applications monitoring social activities of people with depression can contact caregivers as needed and aid providers in patient follow-up [111].

\section{CONCLUDING REMARKS}

In the past, the patient journey for chronic diseases was marred with late diagnosis, "onesize-fits-all" treatment, and access issues creating bottlenecks in the health system. Treatment was often location bound and the patient's life oscillated between hospitals, providers, and healthcare facilities. Unlike in developed countries, healthcare systems in LMICs continue to follow the traditional, provider-driven, diseasefocused approach which must move towards person-centered care integrating patient preferences, needs, and experiences into every phase of the patient journey [112]. In order to create, implement, and support successful patient journey maps, healthcare organizations must have a deep understanding of the populations they serve-as well as those they wish to serve in the future. The patient needs to be recognized as an integral part of this journey and involved in all stages embracing the "nothing for us without us" sentiment [113].

Health systems in LMICs must recognize that the patient journey for NCDs starts long before the onset of symptoms and signs. Strategies designed to improve the patient journey must incorporate the patient-centered perspective at each touchpoint of their journey in the healthcare system: awareness, screening, diagnosis, treatment, and adherence. Effective communication strategies for improving health literacy, patient activation, and incorporation of narrative medicine in physician education positively impact the awareness of patients. Use of appropriate risk assessment tools to tailor therapies, integrated management of chronic illness in primary healthcare, shared decision- making, and decision aids ensure timely and accurate diagnosis. Improved access to NCD treatments, embodying the principles of person-centered care and positive therapeutic alliance, requires commitment at a policy level to deliver safe, affordable, and effective care equitably. Long-term management of NCDs entails substantial self-management of their conditions by patients, which can be augmented by pharmacists and nurse-led interventions. The NCD care continuum pathway needs to move from the traditional acute incident management protocol to a public health approach of prevention and delay of disease onset through early identification and management of risk factors; early diagnosis and appropriate management; and good adherence through effective communication and follow-up. In addition, comprehensive palliative care models must be evaluated and integrated into national health policy and action plans.

Digitization has heralded a healthcare revolution with a patient-centric and user-friendly framework that will undoubtedly increase patient engagement. eCare pathways allow better management of patient journeys by facilitating early and accurate diagnosis at the outset and then on the progress of the disease; aiding in personalized care plans tailored to the patient's genomic makeup and lifestyle; and remote monitoring of patients via digital algorithms to optimize timely treatment interventions. The reduced dependence of digital health on healthcare facilities for care-seeking is an encouraging prospect for LMICs to help bridge gaps in the patient journey for NCDs through empowering patients, improving access to healthcare services, and enhancing efficiency of health systems with innovative, cost-effective, and localized solutions.

\section{ACKNOWLEDGEMENTS}

Funding. This review, the Journal's Rapid Service and Open Access Fees were funded by Upjohn-A Pfizer Division. 
Authorship. All named authors meet the International Committee of Medical Journal Editors (ICMJE) criteria for authorship for this article, take responsibility for the integrity of the work as a whole, and have given their approval for this version to be published.

Medical Writing Assistance. Editorial assistance in the preparation of this article was provided by Tanaya Bharatan, and Kaveri Sidhu, Upjohn-A Pfizer Division and was funded by Upjohn-A Pfizer Division.

Disclosures. Ratna Devi is the Chair Board of Trustees of International Alliance of Patient Organization (IAPO) and Kawaldip Sehmi is the Chief Executive Officer for IAPO. IAPO has received grants from Upjohn-A Pfizer Division. Ratna Devi has received funding from Upjohn, a Pfizer division, that is unrelated to the submitted work. Kannan Subramaniam is an employee of Pfizer. Komal Kanitkar and R. Narendhar have nothing to disclose. The views and opinions expressed in this article are those of the authors. They do not represent or reflect in any way the official policy or position of their current or previous employers.

Compliance with Ethics Guidelines. This article is based on previously conducted studies and does not contain any studies with human participants or animals performed by any of the authors.

Data Availability. Data sharing is not applicable to this article as no datasets were generated or analyzed during the current study.

Open Access. This article is licensed under a Creative Commons Attribution-NonCommercial 4.0 International License, which permits any non-commercial use, sharing, adaptation, distribution and reproduction in any medium or format, as long as you give appropriate credit to the original author(s) and the source, provide a link to the Creative Commons licence, and indicate if changes were made. The images or other third party material in this article are included in the article's Creative Commons licence, unless indicated otherwise in a credit line to the material. If material is not included in the article's Creative Commons licence and your intended use is not permitted by statutory regulation or exceeds the permitted use, you will need to obtain permission directly from the copyright holder. To view a copy of this licence, visit http:// creativecommons.org/licenses/by-nc/4.0/.

\section{REFERENCES}

1. WHO. Noncommunicable diseases: Key facts. World Health Organization. 2018. https://www. who.int/news-room/fact-sheets/detail/ noncommunicable-diseases. Accessed Sept 10, 2020.

2. Kankeu HT, Saksena P, Xu K, Evans DB. The financial burden from non-communicable diseases in low- and middle-income countries: a literature review. Health Res Policy Syst. 2013;11:31.

3. Allen L, Williams J, Townsend N, et al. Socioeconomic status and non-communicable disease behavioural risk factors in low-income and lowermiddle-income countries: a systematic review. Lancet Glob Health. 2017;5(3):e277-e289289.

4. NCD Countdown 2030 collaborators. NCD Countdown 2030: pathways to achieving Sustainable Development Goal target 3.4. Lancet. 2020;396(10255):918-34.

5. Trebble TM, Hansi N, Hydes T, Smith MA, Baker M. Process mapping the patient journey: an introduction. BMJ. 2010;341:c4078.

6. McCarthy S, O'Raghallaigh P, Woodworth S, Lim YL, Kenny LC, Adam F. An integrated patient journey mapping tool for embedding quality in healthcare service reform. J Decis Syst. 2016;25(sup1):354-68.

7. Ben-Tovim DI, Dougherty ML, O'Connell TJ, McGrath KM. Patient journeys: the process of clinical redesign. Med J Aust. 2008;188(S6):S14-S1717.

8. Percival J, McGregor C. An evaluation of understandability of patient journey models in mental health. JMIR Hum Factors. 2016;3(2):e20.

9. Thrift-Perry M, Cabanes A, Cardoso F, Hunt KM, Cruz TA, Faircloth K. Global analysis of metastatic breast cancer policy gaps and advocacy efforts across the patient journey. Breast. 2018;41:93-106. 
10. Mohr P, Galderisi S, Boyer $P$, et al. Value of schizophrenia treatment I: the patient journey. Eur Psychiatry. 2018;53:107-15.

11. Fennelly O, Blake C, FitzGerald O, et al. Advanced musculoskeletal physiotherapy practice: the patient journey and experience. Musculoskelet Sci Pract. 2020;45:102077.

12. Skold CM, Arnheim-Dahlstrom L, Bartley K, et al. Patient journey and treatment patterns in adults with IPF based on health care data in Sweden from 2001 to 2015. Respir Med. 2019;155:72-8.

13. Kassouf W, Aprikian A, Saad F, et al. Improving patient journey and quality of care: summary from the second Bladder Cancer Canada-Canadian Urological Association-Canadian Urologic Oncology Group (BCC-CUA-CUOG) bladder cancer quality of care consensus meeting. Can Urol Assoc J. 2018;12(7):E281-E297297.

14. Alkandari M, Ryan K, Hollywood A. The experiences of people living with peripheral neuropathy in Kuwait-a process map of the patient journey. Pharmacy (Basel). 2019;7(3):127.

15. Checkley W, Ghannem H, Irazola V, et al. Management of NCD in low- and middle-income countries. Glob Heart. 2014;9(4):431-43.

16. Garin N, Koyanagi A, Chatterji S, et al. Global multimorbidity patterns: a cross-sectional, population-based, multi-country study. J Gerontol A Biol Sci Med Sci. 2016;71(2):205-14.

17. Hearn J, Ssinabulya I, Schwartz JI, Akiteng AR, Ross HJ, Cafazzo JA. Self-management of non-communicable diseases in low- and middle-income countries: a scoping review. PLoS One. 2019;14(7): e0219141.

18. Xiao Y. The, "expert patient" approach for noncommunicable disease management in low and middle income settings: when the reality confronts the rhetoric. Chronic Dis Transl Med. 2015;1(3): 145-51.

19. Puteh SEW, Almualm Y. Catastrophic health expenditure among developing countries. Health Syst Policy Res. 2017;4(1). https://doi.org/10.21767/ 2254-9137.100069.

20. Aluttis C, Bishaw T, Frank MW. The workforce for health in a globalized context-global shortages and international migration. Glob Health Action. 2014;7:23611.

21. Xu K, Evans DB, Kawabata K, Zeramdini R, Klavus J, Murray CJ. Household catastrophic health expenditure: a multicountry analysis. Lancet. 2003;362(9378):111-7.
22. Pandey A, Ploubidis GB, Clarke L, Dandona L. Trends in catastrophic health expenditure in India: 1993 to 2014. Bull World Health Organ. 2018;96(1): 18-28.

23. Global Burden of Disease Health Financing Collaborator Network. Evolution and patterns of global health financing 1995-2014: development assistance for health, and government, prepaid private, and out-of-pocket health spending in 184 countries. Lancet. 2017;389(10083):1981-2004.

24. Jayasinghe UW, Harris MF, Parker SM, et al. The impact of health literacy and life style risk factors on health-related quality of life of Australian patients. Health Qual Life Outcomes. 2016;14:68.

25. Chow CK, Teo KK, Rangarajan S, et al. Prevalence, awareness, treatment, and control of hypertension in rural and urban communities in high-, middle-, and low-income countries. JAMA. 2013;310(9): 959-68.

26. Wang Y, McKee M, Torbica A, Stuckler D. Systematic literature review on the spread of health-related misinformation on social media. Soc Sci Med. 2019;240:112552.

27. Duraisamy P. Health status and curative health care in rural India. New Delhi: National Council of Applied Economic Research. 2001. https://demo. ncaer.org/Downloads/WorkingPapers/WP78.pdf. Accessed June 2020.

28. Inche Zainal Abidin S, Sutan R, Shamsuddin K. Prevalence and determinants of appropriate health seeking behaviour among known diabetics: results from a community-based survey. Adv Epidemiol. 2014:793286. https://doi.org/10.1155/2014/ 793286.

29. WHO. Social determinants of health. World Health Organization. 2020. https://www.who.int/social_ determinants/en/. Accessed June 2020.

30. WHO. WHO package of essential noncommunicable (PEN) disease interventions for primary health care. Geneva: World Health Organization; 2020. https://www.who.int/publications/i/item/whopackage-of-essential-noncommunicable-(pen)disease-interventions-for-primary-health-care. Accessed Sept 10, 2020.

31. Bolz-Johnson M, Meek J, Hoogerbrugge N. "Patient Journeys": improving care by patient involvement. Eur J Hum Genet. 2020;28(2):141-3.

32. WHO. Global action plan for the prevention and control of noncommunicable diseases 2013-2020. Geneva: World Health Organization; 2014. https:// apps.who.int/iris/bitstream/handle/10665/94384/ 
9789241506236_eng.pdf?sequence $=1$. Accessed Sept 10, 2020.

33. Stein DJ, Benjet $\mathrm{C}$, Gureje $\mathrm{O}$, et al. Integrating mental health with other non-communicable diseases. BMJ. 2019;364:1295.

34. Kisling LA, Das JM. Prevention strategies. Treasure Island: StatPearls; 2020.

35. Dobe M. Health promotion for prevention and control of non-communicable diseases: unfinished agenda. Indian J Public Health. 2012;56(3):180-6.

36. Srivastava RK, Bachani D. Burden of NCDs, policies and programme for prevention and control of NCDs in India. Indian $\mathrm{J}$ Community Med. 2011;36(Suppl 1):S7-S12.

37. Munday D, Kanth V, Khristi S, Grant L. Integrated management of non-communicable diseases in lowincome settings: palliative care, primary care and community health synergies. BMJ Support Palliat Care. 2019;9(4):e32.

38. WHO. Palliative care. World Health Organization; 2020. https://www.who.int/news-room/fact-sheets/ detail/palliative-care. Accessed Sept 10, 2020.

39. Levesque JF, Harris MF, Russell G. Patient-centred access to health care: conceptualising access at the interface of health systems and populations. Int J Equity Health. 2013;12:18.

40. Ganju A, Goulart AC, Ray A, et al. Systemic solutions for addressing non-communicable diseases in low- and middle-income countries. J Multidiscip Healthc. 2020;13:693-707.

41. WHO. Innovative care for chronic conditions: building blocks for action: global report. Geneva: World Health Organization; 2002. https://www. who.int/chp/knowledge/publications/ icccglobalreport.pdf?ua=1. Accessed June 2020.

42. David R. Changing therapeutic paradigms in glaucoma management. Expert Opin Investig Drugs. 1998;7(7):1063-86.

43. O'Sullivan GA, Yonkler JA, Morgan W, Merritt AP. A field guide to designing a health communication strategy. Baltimore: Johns Hopkins Bloomberg School of Public Health/Center for Communication Programs; 2003.

44. Albert NM, Barnason S, Deswal A, et al. Transitions of care in heart failure: a scientific statement from the American Heart Association. Circ Heart Fail. 2015;8(2):384-409.

45. Hibbard JH, Greene J. What the evidence shows about patient activation: better health outcomes and care experiences; fewer data on costs. Health Aff (Millwood). 2013;32(2):207-14.

46. Irazola VE, Gutierrez L, Bloomfield G, et al. Hypertension prevalence, awareness, treatment, and control in selected LMIC communities: results from the NHLBI/UHG Network of Centers of Excellence for Chronic Diseases. Glob Heart. 2016;11(1):47-59.

47. Clayton LH. Strategies for selecting effective patient nutrition education materials. Nutr Clin Pract. 2010;25(5):436-42.

48. Chang H, Hawley NL, Kalyesubula R, et al. Challenges to hypertension and diabetes management in rural Uganda: a qualitative study with patients, village health team members, and health care professionals. Int J Equity Health. 2019;18(1):38.

49. Bovet P, Chiolero A, Paccaud F, Banatvala N. Screening for cardiovascular disease risk and subsequent management in low and middle income countries: challenges and opportunities. Public Health Rev. 2015;36:13.

50. Mensah GA, Collins PY. Understanding mental health for the prevention and control of cardiovascular diseases. Glob Heart. 2015;10(3):221-4.

51. Godoy L, Hodgkinson S, Robertson HA, et al. Increasing mental health engagement from primary care: the potential role of family navigation. Pediatrics. 2019;143(4):e20182418.

52. Walston J, Buta B, Xue QL. Frailty screening and interventions: considerations for clinical practice. Clin Geriatr Med. 2018;34(1):25-38.

53. International Diabetes Federation. IDF Diabetes Atlas. 9th ed. Brussels: International Diabetes Federation; 2019.

54. Williams B, Mancia G, Spiering W, et al. 2018 ESC/ ESH Guidelines for the management of arterial hypertension: the Task Force for the management of arterial hypertension of the European Society of Cardiology (ESC) and the European Society of Hypertension (ESH). Eur Heart J. 2018;39(33): 3021-104.

55. Blaha MJ. Personalizing treatment: between primary and secondary prevention. Am J Cardiol. 2016;118(6 Suppl):4A-12A.

56. National Academies of Sciences, Engineering, and Medicine. Improving diagnosis in health care. Washington, DC: The National Academies Press; 2015.

57. Allen LA, Stevenson LW, Grady KL, et al. Decision making in advanced heart failure: a scientific 
statement from the American Heart Association. Circulation. 2012;125(15):1928-52.

58. Padilla LM, Creem-Regehr SH, Hegarty M, Stefanucci JK. Decision making with visualizations: a cognitive framework across disciplines. Cogn Res Princ Implic. 2018;3:29.

59. O'Connor AM, Wennberg JE, Legare F, et al. Toward the 'tipping point': decision aids and informed patient choice. Health Aff (Millwood). 2007;26(3): 716-25.

60. Field MJ, Lohr KN, editors. Clinical practice guidelines: directions for a new program. Washington, DC: National Academies Press; 1990.

61. Beaglehole R, Epping-Jordan J, Patel V, et al. Improving the prevention and management of chronic disease in low-income and middle-income countries: a priority for primary health care. Lancet. 2008;372(9642):940-9.

62. Beran D, Pedersen HB, Robertson J. Noncommunicable diseases, access to essential medicines and universal health coverage. Glob Health Action. 2019;12(1):1670014.

63. Amelung V, Stein V, Goodwin N, Balicer R, Nolte E, Suter E. Handbook integrated care. Cham: Springer International; 2017.

64. Small N, Bower P, Chew-Graham CA, Whalley D, Protheroe J. Patient empowerment in long-term conditions: development and preliminary testing of a new measure. BMC Health Serv Res. 2013;13:263.

65. Ardito RB, Rabellino D. Therapeutic alliance and outcome of psychotherapy: historical excursus, measurements, and prospects for research. Front Psychol. 2011;2:270.

66. Allen ML, Cook BL, Carson N, Interian A, La Roche M, Alegria M. Patient-provider therapeutic alliance contributes to patient activation in community mental health clinics. Adm Policy Ment Health. 2017;44(4):431-40.

67. Subramanian S, Hirsch IB. Personalized diabetes management: moving from algorithmic to individualized therapy. Diabetes Spectr. 2014;27(2):87-91.

68. Verloo H, Chiolero A, Kiszio B, Kampel T, Santschi V. Nurse interventions to improve medication adherence among discharged older adults: a systematic review. Age Ageing. 2017;46(5):747-54.

69. Jeong S, Lee M, Ji E. Effect of pharmaceutical care interventions on glycemic control in patients with diabetes: a systematic review and meta-analysis. Ther Clin Risk Manag. 2018;14:1813-29.
70. Newman PM, Franke MF, Arrieta J, et al. Community health workers improve disease control and medication adherence among patients with diabetes and/or hypertension in Chiapas, Mexico: an observational stepped-wedge study. BMJ Glob Health. 2018;3(1):e000566.

71. Ganguli A, Clewell J, Shillington AC. The impact of patient support programs on adherence, clinical, humanistic, and economic patient outcomes: a targeted systematic review. Patient Prefer Adherence. 2016;10:711-25.

72. Ddungu H. Palliative care: what approaches are suitable in developing countries? $\mathrm{Br} \mathrm{J}$ Haematol. 2011;154(6):728-35.

73. Poudel A, Kc B, Shrestha S, Nissen L. Access to palliative care: discrepancy among low-income and high-income countries. J Glob Health. 2019;9(2): 020309.

74. Dunn J, Runge R, Snyder M. Wearables and the medical revolution. Pers Med. 2018;15(5):429-48.

75. Bates DW, Saria S, Ohno-Machado L, Shah A, Escobar G. Big data in health care: using analytics to identify and manage high-risk and high-cost patients. Health Aff (Millwood). 2014;33(7): 1123-31.

76. Bastawrous A, Armstrong MJ. Mobile health use in low- and high-income countries: an overview of the peer-reviewed literature. J R Soc Med. 2013;106(4): $130-42$.

77. Widmer RJ, Collins NM, Collins CS, West CP, Lerman LO, Lerman A. Digital health interventions for the prevention of cardiovascular disease: a systematic review and meta-analysis. Mayo Clin Proc. 2015;90(4):469-80.

78. World Health Organization. WHO guideline: recommendations on digital interventions for health system strengthening. Geneva: World Health Organization; 2019. https://apps.who.int/iris/ bitstream/handle/10665/311941/9789241550505eng.pdf?ua=1. Accessed June 2020.

79. Ratzan SC, Weinberger MB, Apfel F, Kocharian G. The digital health scorecard: a new health literacy metric for NCD prevention and care. Glob Heart. 2013;8(2):171-9.

80. Greaves CJ, Campbell JL. Supporting self-care in general practice. Br J Gen Pract. 2007;57(543): 814-21.

81. Hobbs FD. Cardiovascular disease: different strategies for primary and secondary prevention? Heart. 2004;90(10):1217-23. 
82. Olczuk D, Priefer R. A history of continuous glucose monitors (CGMs) in self-monitoring of diabetes mellitus. Diabetes Metab Syndr. 2018;12(2):181-7.

83. Kario K, Park S, Buranakitjaroen P, et al. Guidance on home blood pressure monitoring: a statement of the HOPE Asia Network. J Clin Hypertens (Greenwich). 2018;20(3):456-61.

84. Otlowski M, Taylor S, Bombard Y. Genetic discrimination: international perspectives. Annu Rev Genom Hum Genet. 2012;13:433-54.

85. GBD 2016 Disease and Injury Incidence and Prevalence Collaborators. Global, regional, and national incidence, prevalence, and years lived with disability for 328 diseases and injuries for 195 countries, 1990-2016: a systematic analysis for the Global Burden of Disease Study 2016. Lancet. 2017;390(10100):1211-59.

86. World Health Organization. World health statistics 2020: monitoring health for the SDGs, sustainable development goals. World Health Organization; 2020. https://apps.who.int/iris/handle/10665/ 332070. Accessed June 2020.

87. Bitton A, Fifield J, Ratcliffe $\mathrm{H}$, et al. Primary healthcare system performance in low-income and middle-income countries: a scoping review of the evidence from 2010 to 2017. BMJ Glob Health. 2019;4(Suppl 8):e001551.

88. Doyle C, Lennox L, Bell D. A systematic review of evidence on the links between patient experience and clinical safety and effectiveness. BMJ Open. 2013;3(1):e001570.

89. Blythe A. The patient journey-patient-oriented approaches to care. 2016. https://www.ausmed. com/cpd/articles/the-patient-journey. Accessed June 2020 .

90. Pomey MP, Ghadiri DP, Karazivan P, Fernandez N, Clavel N. Patients as partners: a qualitative study of patients' engagement in their health care. PLoS One. 2015;10(4):e0122499.

91. National Research Council (US), Institute of Medicine (US). In: Woolf SH, Aron L, editors. Health in international perspective: shorter lives, poorer health. Washington (DC): National Academies Press; 2013.

92. Tattersall RL. The expert patient: a new approach to chronic disease management for the twenty-first century. Clin Med (Lond). 2002;2(3):227-9.

93. Fromer L. Implementing chronic care for COPD: planned visits, care coordination, and patient empowerment for improved outcomes. Int J Chron Obstruct Pulmon Dis. 2011;6:605-14.
94. MoPoTsyo. Peer Education. 2010. https://www. mopotsyo.org/peereducation.html. Accessed July 28,2020 .

95. Van Olmen J, Marie KG, Christian D, et al. Content, participants and outcomes of three diabetes care programmes in three low and middle income countries. Prim Care Diabetes. 2015;9(3):196-202.

96. Larentis AV, Barbosa DNF, da Silva CR, Barbosa JLV. Applied computing to education on noncommunicable chronic diseases: a systematic mapping study. Telemed J E Health. 2020;26(2):147-63.

97. Joseph-Shehu EM, Ncama BP, Mooi N, MashambaThompson TP. The use of information and communication technologies to promote healthy lifestyle behaviour: a systematic scoping review. BMJ Open. 2019;9(10):e029872.

98. Vianna HD, Barbosa JLV. Pompilos, a model for augmenting health assistant applications with social media content. J Univ Comput Sci. 2020;21(1):4-32.

99. Bhattacharyya O, Mossman K. Technological innovations for aging populations: what are the opportunities for learning across low- and high-income countries? Health Manag Policy Innov. 2018;3(1).

100. Vianna HD, Barbosa JLVV, Pittoli F. In the pursuit of Hygge Software. IEEE Softw. 2017;34(6):48-52.

101. Keesara S, Jonas A, Schulman K. Covid-19 and health care's digital revolution. $N$ Engl J Med. 2020;382(23):e82.

102. World Health Organization. COVID-19 and NCDs. 2020. https://www.who.int/publications/m/item/ rapid-assessment-of-service-delivery-for-ncdsduring-the-covid-19-pandemic. Accessed Aug 3, 2020.

103. Kretchy IA, Asiedu-Danso M, Kretchy JP. Medication management and adherence during the COVID-19 pandemic: perspectives and experiences from low-and middle-income countries. Res Social Adm Pharm. 2020. https://doi.org/10.1016/j. sapharm.2020.04.007.

104. World Health Organization. Maintaining essential health services: operational guidance for the COVID-19 context. 2020. https://www.who.int/ publications/i/item/10665-332240. Accessed Aug 3, 2020 .

105. Mathur P, Rangamani S. COVID-19 and noncommunicable diseases: identifying research priorities to strengthen public health response. Int J Noncommun Dis. 2020;5(2):76-82. 
106. Pariyo GW, Wosu AC, Gibson DG, Labrique AB, Ali J, Hyder AA. Moving the agenda on noncommunicable diseases: policy implications of mobile phone surveys in low and middle-income countries. J Med Internet Res. 2017;19(5):e115.

107. Haregu TN, Byrnes A, Singh K, et al. A scoping review of non-communicable disease research capacity strengthening initiatives in low and middle-income countries. Glob Health Res Policy. 2019;4:31.

108. Frankish H, Boyce N, Horton R. Mental health for all: a global goal. Lancet. 2018;392(10157):1493-4.

109. Dias LPS, Barbosa JLV, Feijo LP, Vianna HD. Development and testing of iAware model for ubiquitous care of patients with symptoms of stress, anxiety and depression. Comput Methods Programs Biomed. 2020;187:105113.
110. Bavaresco R, Barbosa J, Vianna H, Buttenbender P, Dias L. Design and evaluation of a context-aware model based on psychophysiology. Comput Methods Programs Biomed. 2020;189:105299.

111. Petry MM, Barbosa JLV, Rigo SJ, Dias LPS, Büttenbender PC. Toward a ubiquitous model to assist the treatment of people with depression. Univ Access Inf Soc. 2020;19:841-54.

112. Bokhour BG, Fix GM, Mueller NM, et al. How can healthcare organizations implement patient-centered care? Examining a large-scale cultural transformation. BMC Health Serv Res. 2018;18(1):168.

113. Paul T. "Nothing about us without us": toward patient- and family-centered care. AMA J Ethics. 2016;18(1):3-5. 